\title{
Oxidation studies of Al alloys: Part II Al-Mg alloy
}

\author{
G. Wu ${ }^{\mathrm{a}}$, K. Dash ${ }^{\mathrm{a}, \mathrm{b} *}$, M.L. Galano ${ }^{\mathrm{a} *}$, K.A.Q. O’Reilly ${ }^{\mathrm{a} *}$ \\ a Department of Materials, University of Oxford, Parks Road, Oxford OX1 3PH, U.K. \\ b Department of Materials Engineering, Indian Institute of Science, Bangalore-560012, India
}

\section{Corresponding Authors}

Khushbu Dash

Department of Materials Engineering,

Indian Institute of Science, Bangalore-560012, India

khushbudash@iisc.ac.in

Marina Galano

Department of Materials, University of Oxford

marina.galano@materials.ox.ac.uk

Keyna O'Reilly

Department of Materials, University of Oxford

keyna.oreilly@materials.ox.ac.uk

\begin{abstract}
The oxidation behaviour of molten Al-Mg alloys has been investigated. The oxides formed were extracted from the alloys using a novel extraction method and the oxidation mechanisms are discussed with reference to the growth behaviour of the oxides. The oxides formed in Al$\mathrm{Mg}$ alloys were explored by scanning electron microscopy, X-ray diffraction and photoelectron spectroscopy. Thermodynamic calculations were performed to predict the feasibility of the reactions giving rise to oxides and to explain the oxide formation under various experimental conditions. The formation of $\mathrm{MgAl}_{2} \mathrm{O}_{4}$ was followed by formation of $\mathrm{MgO}$ as a function of time leading to depletion of $\mathrm{Mg}$.
\end{abstract}

Keywords: Oxidation; X-ray photoelectron spectroscopy; Oxidation Kinetics; Thermodynamics.

\section{Introduction}

Clean Al surfaces rapidly get covered with a thin layer of amorphous aluminium oxide when exposed to an oxygen-containing environment at temperatures below $300^{\circ} \mathrm{C}$ [1-4]. The growth 
mechanism of the amorphous oxide layer is still unknown, but it is suggested that the formation of the amorphous layer may contain three stages: oxygen atoms bombard onto the free surface and form bonds with $\mathrm{Al}$ atoms through both physisorption and chemisorption [5,6]; individual oxide islands nucleate and grow laterally to cover the whole surface and form a continuous layer; the layer then grows to a certain thickness [7,8]. The thickness of the naturally formed amorphous aluminium oxide layer has been found to be limited. TEM was used to characterize the oxide scale formed on single crystal $\mathrm{Al}$ at $500^{\circ} \mathrm{C}$ in air, which reported that plate-like crystalline oxides grow at the metal/oxide interface and the crystalline oxides were identified to be face-centred cubic with a lattice parameter of $0.79 \mathrm{~nm}$, i.e. $\quad \gamma-\mathrm{Al}_{2} \mathrm{O}_{3}$. In addition, they also observed that the crystalline oxides grow into the metal with an epitaxial relationship (110) [110] $\gamma-\mathrm{Al}_{2} \mathrm{O}_{3} / /$ (111) [110] $\mathrm{Al}$ [9]. Eldridge et al. [10] later found that crystalline $\gamma-\mathrm{Al}_{2} \mathrm{O}_{3}$ oxides could both grow laterally, and inwardly into the metal, depending on the crystal orientation of the metal substrate.

Using an ${ }^{18} \mathrm{O} / \mathrm{SIMS}$ technique (tracer marking), Eldridge et al. [10] also suggested that the growth of crystalline $\gamma-\mathrm{Al}_{2} \mathrm{O}_{3}$ oxides at temperatures above $500^{\circ} \mathrm{C}$ may be controlled by the inward diffusion of oxygen and proposed that there are some easy paths for inward diffusion of oxygen within the oxide scale. Shimizu et al. [11,12] found that $\gamma-\mathrm{Al}_{2} \mathrm{O}_{3}$ crystals preferentially nucleated at ridge-like sites and suggested that the easy diffusion paths for oxygen proposed by Eldridge et al. [10] could be the microcracks generated at these ridges due to stress concentration. It can be inferred from the literature that the mechanism of oxidation in the liquid state may be significantly different from the solid state oxidation mechanisms discussed above. Unfortunately, there is currently no well-agreed theory. Oxidation of molten metals can be complex for several reasons: for example, there may be enhanced transport of metallic species to the surface [13], which could potentially change the oxidation thermodynamics; and the melt surface is also subject to a certain level of disturbance, which could potentially disrupt the scale morphology and affect the kinetics to an unknown extent [14]. It was also found that the oxidation kinetics were best described by a logarithmic law at temperatures below $750^{\circ} \mathrm{C}$ and by a parabolic law at temperatures above $750^{\circ} \mathrm{C}$. It was also suggested that parabolic growth is controlled by the outward diffusion of $\mathrm{Al}$ ions through the oxide film to the oxygen/oxide interface.

$\mathrm{Mg}$ is the main alloying element in commercial 5xxx series wrought $\mathrm{Al}$ alloys. Al-Mg alloys have excellent corrosion resistance and $\mathrm{Mg}$ improves the mechanical properties of $\mathrm{Al}$ [15]. However, $\mathrm{Mg}$ can be readily selectively oxidized during melting or casting due to its higher affinity for oxygen than $\mathrm{Al}[16]$. As suggested by the literature, the formation of $\operatorname{MgO}[17,18]$ 
or $\mathrm{MgAl}_{2} \mathrm{O}_{4}$ (also known as spinel) [19], or both [20,21], are often observed in the oxide scales formed on Al-Mg alloys. Kinetically, the various oxide growth laws for long and short oxidation times reported by researchers [22-27] may imply that there is no generally agreed rate law and that the oxidation of Al-Mg alloys may be controlled by a mixture of mechanisms instead of a single mechanism.

Recent studies on Al-Mg oxidation shows addition of $\mathrm{Al}_{2} \mathrm{Ca}$ renders passivation onto the surface of Al-Mg alloys and yields a Pilling-Bedworth ratio of 1 . Al-7.5Mg alloy shows existence of $\mathrm{MgO}$ during initial periods of oxidation; later stage of oxidation shows spinel formation [28]. Ha et al [29,30] also showed that Ca addition improves oxidation resistance. Weight gain in case of $\mathrm{Al}-\mathrm{Mg}$ alloys increased with $\mathrm{Mg}$ content by internal oxidation, which has been studied by Hagin et al. [31]. Addition of Ca triggered the formation of oxide blisters driven by growth of $\mathrm{MgO}$ and $\mathrm{MgAl}_{2} \mathrm{O}_{4}$ [32]. All intermetallic compounds contribute to forming a compact oxide layer which slows down the Mg atoms' outward diffusion.

In this investigation, efforts have been made to understand the oxidation mechanisms of Al$\mathrm{Mg}$ alloys, particularly of molten $\mathrm{Al}-\mathrm{Mg}$ alloys, in terms of oxidation thermodynamics, growth kinetics and oxide microstructures. Characterization methods such as X-ray diffraction (XRD), scanning electron microscopy (SEM) and X-ray photoelectron spectroscopy (XPS) have been employed to study extracted oxides.

\section{Experimental details}

\section{Oxidation behaviour}

$\mathrm{Al}-0.2 \mathrm{wt} . \% \mathrm{Mg}$ and $\mathrm{Al}-2 \mathrm{wt} . \% \mathrm{Mg}$ alloys were oxidised in a furnace in dry air at $750^{\circ} \mathrm{C}$ for 1 hour and then studied using SEM. SEM and EDX have been combined to study the oxide scales formed on the Al-Mg alloys in terms of oxide morphology and chemistry. The surface of an oxidized sample is usually microscopically rough, and the interpretation of EDX results should always take into account the specific conditions (such as local topography, interaction volume size, etc) under which the spectrum was obtained.

\section{Skimming of oxides}

To observe the oxide layer closely, an $\mathrm{Al}-0.2 \mathrm{Mg}$ or $\mathrm{Al}-2 \mathrm{Mg}$ sample was initially heated to $750^{\circ} \mathrm{C}$ and the surface oxide was then carefully skimmed away using a K-type thermocouple 
probe with tip diameter of $1 \mathrm{~mm}$. This would allow the oxidation progress to be set back to the start and expose fresh melt to the atmosphere. The skimmed sample was then isothermally held at $750^{\circ} \mathrm{C}$ for 5 or 10 minutes and was observed in the SEM after cooling to room temperature.

\section{Extraction of oxides}

It has been shown that intermetallic phases can be extracted from an $\mathrm{Al}$ alloy by dissolving away the $\alpha$-Al matrix using anhydrous butanol in an argon environment and our group has reported a number of papers using this technique to extract intermetallic phases of interest from different Al alloys [33, 34]. Recently, our group has extended the use of this technique to extract the oxide films and particles from oxidized samples. The butanol dissolves away the Al matrix $(\alpha-\mathrm{Al})$ through the following chemical reaction:

$2 \mathrm{Al}+6 \mathrm{C}_{4} \mathrm{H}_{9} \mathrm{OH} \rightarrow 2 \mathrm{Al}\left(\mathrm{C}_{4} \mathrm{H}_{9} \mathrm{O}\right)_{3}+3 \mathrm{H}_{2}$

For each extraction, $0.42 \mathrm{~g}$ of material was used. Before the extraction, some filings of pure $\mathrm{Al}$ were added to the butanol before it was refluxed for 3 hours to ensure it was anhydrous. An autoclave was used to facilitate the process. All the components were cleaned ultrasonically in deionized water and then dried in an oven at $175^{\circ} \mathrm{C}$. A filter paper with a pore size of $0.2 \mu \mathrm{m}$ was placed inside the autoclave to collect the extracted oxides. The autoclave was then evacuated, filled with argon and $80 \mathrm{ml}$ of the anhydrous butanol added. The autoclave was sealed and held at $135^{\circ} \mathrm{C}$ for around 5 hours to allow complete reaction between the $\alpha$-Al matrix and the anhydrous butanol. Once completed, the autoclave was dismantled and the filter paper containing the oxide phases was removed. Electrically conductive disc-shaped carbon adhesive tabs were pressed on to cylindrical stubs with a $12.5 \mathrm{~mm}$ diameter and a $10 \mathrm{~mm}$ height. Extracted oxides were scrapped from the dried filter onto these tabs and then coated with a platinum film of thickness $\sim 2 \mathrm{~nm}$ before SEM examination.

\section{Characterization}

XPS analysis was performed on $A l-A P$ (as polished pure Al sample), $A l-2 M g-A P$ (as polished Al-2Mg sample), $A l-2 M g-R l$ (Al-2Mg sample oxidized at $750^{\circ} \mathrm{C}$ in air for $1 \mathrm{~h}$ ) and $A l-2 M g-R 6$ (Al-2Mg sample oxidized at $750^{\circ} \mathrm{C}$ in air for $6 \mathrm{~h}$ ). Two different $\mathrm{X}$-ray sources ( $\mathrm{Al} \mathrm{K} \alpha$ and $\mathrm{Mg}$ $\mathrm{K} \alpha$ ) were used during the experiments. The oxidation kinetics of $\mathrm{Al}, \mathrm{Al}-0.2 \mathrm{Mg}$ and $\mathrm{Al}-2 \mathrm{Mg}$ were studied using a Perkin Elmer thermogravimetric/differential thermal analysis (TG/DTA) facility to measure the weight gain curves of the alloys while being isothermally held at 
different holding temperatures. The sensitivity value of the microbalance is $0.1 \mu \mathrm{g}$ and the weight of each disc-shaped specimen for each TGA experiment was around $50 \mathrm{mg}$ for a diameter of $3 \mathrm{~mm}$. The atmosphere was closely controlled using an air flush of $20 \mathrm{cc} \mathrm{min}^{-1}$. The weight gain was recorded every second. Thermodynamic calculations were performed and the growth behaviour of $\mathrm{MgO}$ and $\mathrm{MgAl}_{2} \mathrm{O}_{4}$ is discussed with reference to thermodynamic aspects and theory.

\section{Results and discussion}

\subsection{Scanning electron microscopy}

\section{Al-0.2Mg - nodule morphology}

Figure 1(a) shows the surface oxide layer morphology of an Al-0.2Mg sample which was oxidized at $750^{\circ} \mathrm{C}$ for $1 \mathrm{~h}$. The oxide layer consists of $1-2 \mu \mathrm{m}$ crystalline particles, exhibiting an overall "nodule" morphology and powdery topography. During solidification, significant thermal stress builds up in the oxide scale [35], cracking is an effective way to release the stress (Figure 1(b)). In the literature EDX analysis has been used to identify $\mathrm{MgO}$ and $\mathrm{MgAl}_{2} \mathrm{O}_{4}$ oxides [26, 27], which are two of the important oxides in the Al-Mg- $\mathrm{O}_{2}$ system. Ideally, the stoichiometric weight ratio of $\mathrm{Mg}$ to $\mathrm{O}$ in $\mathrm{MgO}$ and $\mathrm{MgAl}_{2} \mathrm{O}_{4}$ is 1.5 and 0.375 respectively. It has been suggested that if the $\mathrm{Mg} / \mathrm{O}$ ratio is less than 0.4 , the oxide is highly likely to be $\mathrm{MgAl}_{2} \mathrm{O}_{4}$-rich oxide, if the $\mathrm{Mg} / \mathrm{O}$ ratio is more than 1 , the oxide consists of a high percentage of pure $\mathrm{MgO}$ [27]. But again, the conditions of the EDX analysis must be taken into account, including the topography, interaction volume, etc, in order to avoid misinterpretation of the results. From Figure 1(a), these loosely packed particles contain $\mathrm{Mg}$ and $\mathrm{O}$ with an average weight ratio of around 0.52 , indicating a possible combination of both $\mathrm{MgO}$ and $\mathrm{MgAl}_{2} \mathrm{O}_{4}$. From Figure 1(b), the chemistry at the exposed metal interface indicates $\mathrm{Mg}$ weight concentration of $1.05 \%$, which is higher than the initial bulk $\mathrm{Mg}$ composition $(0.2 \%)$, suggesting the preferential segregation of $\mathrm{Mg}$ to the surface region during oxidation. As suggested by the EDX results in Figure 1(b), the 1-2 $\mu$ m nodule-like oxide particles mainly comprise of $\mathrm{MgAl}_{2} \mathrm{O}_{4}$.

\section{Al-2Mg - wrinkled morphology}

Figure 2(a) shows the surface oxide layer morphology of an Al-2Mg sample which was oxidized at $750^{\circ} \mathrm{C}$ in air for $1 \mathrm{~h}$. It can be seen that the surface oxide layer has a wrinkled morphology with snake-like ridges. From Figure 2(a), it can be seen that there are cauliflower- 
like bulges consisting of agglomerates of spherical oxides less than $1 \mu \mathrm{m}$ in diameter, which protrude out of the oxide layer. EDX analysis was performed on these features. As shown in Figures 2(a \& b), EDX spectra of these features (P1-P3) suggest they are richer in both Mg and $\mathrm{O}$, compared to the main oxide chemistry (P4). From Figure 2(b), the $\mathrm{Mg} / \mathrm{O}$ weight ratio for spectra P1-P3 are 1.30, 1.01, and 1.36 respectively, suggesting the cauliflower-like bulges are likely to contain $\mathrm{MgO}$. The chemistry of the main oxide, as indicated by $\mathrm{P} 4$, is more certainly an average chemistry from both the oxide layer and the metal underneath: for $\mathrm{MgAl}_{2} \mathrm{O}_{4}$, the $\mathrm{Mg} / \mathrm{Al}$ weight ratios is around 0.44 , in this case, the $\mathrm{Mg} / \mathrm{Al}$ ratio is only 0.34 , and $\mathrm{Mg} / \mathrm{O}$ ratio is 0.66 implying that $\mathrm{X}$-ray signals are also coming from the metallic Al beneath the oxide layer.

The $\mathrm{MgO}$ to $\mathrm{MgAl}_{2} \mathrm{O}_{4}$ transformation has been suggested by Haginoya and Fukusako [21], Impey et al. [22] and Venugopalan et al. [22]. After a long period of oxidation time such as 24 hours, the consumption of $\mathrm{Mg}$ to form $\mathrm{MgO}$ may lower the surface $\mathrm{Mg}$ composition to a level where spinel becomes the most favourable oxide to form. It is therefore hypothesized here that the oxidation of the Al-Mg alloys may proceed in the order from $\mathrm{MgO}$ to $\mathrm{MgAl}_{2} \mathrm{O}_{4}$.

\subsection{Extraction of oxides}

In the present work, a novel method is introduced to directly observe the morphology of the "wet" side of an oxide layer (the metal/oxide interface) and the "dry" side of an oxide layer (the oxide/air interface) by using an extraction method. Extraction is done to capture the structure of the surface oxide scale at the very early stage (a few minutes) of oxidation.

Skimming was used to reset the oxidation back to the beginning. The oxidation proceeds firstly by the formation of an amorphous aluminium oxide layer on the melt [36,37].

Figure 3(a) shows the morphologies of both sides of the oxide layer formed on an Al- $0.2 \mathrm{Mg}$ melt which was held at $750^{\circ} \mathrm{C}$ for 5 minutes after skimming. It looks like the dry side of the oxide layer is mostly intact while oxide-like particles have already nucleated and grown on the wet side.

Figure 3(b) is a secondary electron (SE) image showing the dry side (the oxide/air interface) morphology of the oxide layer formed on an $\mathrm{Al}-0.2 \mathrm{Mg}$ sample which was held at $750^{\circ} \mathrm{C}$ for 10 minutes after skimming. It is very interesting to notice the formation of spherical nanoparticles averaging between 30-600 $\mathrm{nm}$ in diameter. The growth of these nanoparticles causes microcracks around the particles averaging 1-3 $\mu \mathrm{m}$ long within the continuous oxide layer. Figure 3(b) also suggests that nanoparticles may initially nucleate at the metal/oxide interface and within the initial amorphous oxide layer, and then grow towards the oxide/air interface. 
This is consistent with the model proposed by Shimizu et al. [38] and Panda et al. [39] that $\mathrm{MgO}$ forms and cracks the initially formed aluminium oxide layer in the early stage of oxidation (usually in a time less than 5 minutes). This mechanism is further supported by the XPS results described later. Figure 3(c) is an SE image showing the morphology of the wet side of the oxide layer formed on the Al- $0.2 \mathrm{Mg}$ sample which was held at $750^{\circ} \mathrm{C}$ for only 5 minutes after skimming, which features a complex microstructure consisting of both oxides and intermetallic-like substances. It is noted that the wet side of the oxide layer also contains of spherical nanoparticles: at the area where P1 was taken, the average particle size is around $1 \mu \mathrm{m}$; where P2 was taken, the average particle size is less than $400 \mathrm{~nm}$. P3 shows a region where $\mathrm{Al}$ and $\mathrm{O}$ are dominant suggesting that it is in fact alumina. This suggests that the oxides grow preferentially in local regions instead of growing uniformly everywhere. The chemistry of these particles indicates that the oxides mainly consist of $\mathrm{MgO}$, as suggested qualitatively by the EDX spectra in Figure 3(d).

\subsection{XPS}

XPS studies were carried out to understand what type of oxide forms naturally on fresh surfaces of $\mathrm{Al}-\mathrm{Mg}$ alloys, and to confirm the transformation of aluminium oxide to $\mathrm{MgO}$ within the oxide scale, as suggested by the SEM/EDX results. All XPS peaks were labelled according to references [26,27].

\section{Wide scan}

The wide scan XPS spectra acquired using Mg K $\alpha$ X-rays are shown in Figure 4(a) illustrating the surface oxide formed on $A l-A P$ and $A l-2 M g-A P$ is aluminium oxide, as indicated by the presence of $\mathrm{Al} 2 \mathrm{p} \& \mathrm{Al} 2 \mathrm{~s}$ peaks and the absence of $\mathrm{Mg} 2 \mathrm{p} \& \mathrm{Mg} 2 \mathrm{~s}$ peaks. While the surface oxide formed on $A l-2 M g-R l$ and $A l-2 M g-R 6$ is $\mathrm{MgO}$, as confirmed by the presence of $\mathrm{Mg} 2 \mathrm{p}$ $\& \mathrm{Mg} 2 \mathrm{~s}$ peaks and the absence of $\mathrm{Al} 2 \mathrm{p} \& \mathrm{Al} 2 \mathrm{~s}$ peaks. The results imply that $\mathrm{Al}_{2} \mathrm{O}_{3}$ is the first oxide naturally formed on free surfaces of dilute Al-Mg alloys. A possible qualitative explanation for this finding may be established based on the Cabrera-Mott theory [40]: when the oxide layer is thinner than $5 \mathrm{~nm}$, an electric field of approximately 1 or 2 volts is established across the oxide layer and the kinetics of oxide growth are controlled by the outward transport of metal ions [48]: the trivalent $\mathrm{Al}$ ions $\left(\mathrm{Al}^{3+}\right)$ simply move faster to the oxide/air interface to bond with oxygen than divalent $\mathrm{Mg}$ ions $\left(\mathrm{Mg}^{2+}\right)$ under the same electric field.

Figure 4(b) shows the wide scan XPS spectra acquired with Al Ka X-rays, whose energy $(1486.6 \mathrm{eV})$ is higher than that of $\mathrm{Mg} \mathrm{K \alpha}$ X-rays $(1253.6 \mathrm{eV})$. It has been shown that Mg KLL is very sensitive to $\mathrm{Al} \mathrm{K} \alpha$ [41]. In the present work, $\mathrm{Mg}$ Auger peaks (Mg KLL) are not 
observed in the spectra of $A l-A P$ and $A l-2 M g-A P$, suggesting a near complete absence of $\mathrm{Mg}$ in the surface oxide layer; while Mg KLL peaks are clearly identified in the spectra of $A l-2 M g$ $R 1$ and $A l-2 M g-R 6$, suggesting the formation of an $\mathrm{Mg}$-rich oxide layer on the top surface. Given the fact that the depth of information of XPS analysis is around $10 \mathrm{~nm}$ [41], it can be concluded that $\mathrm{MgO}$ is the main oxide formed on $A l-2 M g-R l$ and $A l-2 M g-R 6$, at least the external part of the oxide layer; while the top surface oxide of $A l-A P$ and $A l 2 M g-A P$ is $\mathrm{Al}_{2} \mathrm{O}_{3}$. Interestingly, the $\mathrm{O} 1 \mathrm{~s}$ " $g h o s t$ " peak is observed in the spectra of $A l-2 M g-R I$ and $A l-2 M g-R 6$. This type of peak is identified as a magnesium induced "ghost" peak [42]. When a sample containing $\mathrm{Mg}$ is irradiated with $\mathrm{Al} \mathrm{K} \alpha \mathrm{X}$-rays, photoelectrons interact with the sample to produce $\mathrm{Mg} \mathrm{K \alpha} . \mathrm{Mg} \mathrm{K} \alpha$ can cause further emission of photoelectrons. In the present work, the binding energy of these $\mathrm{Mg} \mathrm{K \alpha}$ induced $\mathrm{O}$ 1s photoelectrons is observed at approximately 766 $\mathrm{eV}$, as highlighted in Figure 4(b). This is because the kinetic energy of the induced $\mathrm{O} 1 \mathrm{~s}$ photoelectrons is approximately $1253.6 \mathrm{eV}-532.5 \mathrm{eV}(\mathrm{O} 1 \mathrm{~s}$ binding energy $)=721.1 \mathrm{eV}$ so they would appear at around $1486.6 \mathrm{eV}-721.1 \mathrm{eV}=765.5 \mathrm{eV}$ in the spectrum.

\section{Core levels}

\section{(a) Al 2p}

From Figure 4(c), the elemental Al 2p peaks are located at a binding energy of $72.82 \mathrm{eV}$ for $\mathrm{Mg} \mathrm{K} \alpha$ irradiation and $72.81 \mathrm{eV}$ for $\mathrm{Al} \mathrm{K \alpha}$ irradiation. The oxide $\mathrm{Al} 2 \mathrm{p}$ peaks are located at binding energies of $75.86 \mathrm{eV}(\mathrm{Mg} \mathrm{K} \alpha)$ and $75.88 \mathrm{eV}(\mathrm{Al} \mathrm{K \alpha})$. The ratio of the areas under the fitted elemental $\mathrm{Al} 2 \mathrm{p}$ peak and the oxide $\mathrm{Al} 2 \mathrm{p}$ peak is 1:6.45 (using $\mathrm{Mg} \mathrm{K} \alpha$ ) and 1:5.57 (using $\mathrm{Al} \mathrm{K} \alpha$ ), respectively. It is noted that the ratio is slightly higher in the Al $\mathrm{K} \alpha$ irradiated sample. This is due to the higher X-ray energy ( $\mathrm{Al} \mathrm{K} \alpha-1453.6 \mathrm{eV}$ ), causing more emission of photoelectrons from the metal underneath.

\section{(b) $01 \mathrm{~s}$}

The $\mathrm{O}$ 1s peaks were fitted with Gaussian functions. In the present work, as shown in Figure 4(d), the $\mathrm{O} 1 \mathrm{~s}$ peaks at $530.01 \mathrm{eV}(A l-2 M g-R 1, \mathrm{Mg} \mathrm{K \alpha})$ and $529.98 \mathrm{eV}(A l-2 M g-R 6, \mathrm{Mg} \mathrm{K \alpha})$ are attributed to the $\mathrm{O}$ from $\mathrm{MgO}$, while the $\mathrm{O}$ 1s peaks at higher binding energies of 532.18 $\mathrm{eV}(A l-2 M g-R l, \mathrm{Mg} \mathrm{K} \alpha)$ and $532.20 \mathrm{eV}(A l-2 M g-R 6, \mathrm{Mg} \mathrm{K} \alpha)$ are attributed to the $\mathrm{O}$ from the hydroxide species, $\mathrm{Mg}(\mathrm{OH})_{2}$. It has been shown that $\mathrm{Mg}(\mathrm{OH})_{2}$ forms naturally on the $\mathrm{MgO}$ layer once the sample is exposed to a humid environment and even after short periods of exposure to a humid atmosphere, the sample surfaces could form an appreciable level of 
$\mathrm{Mg}(\mathrm{OH})_{2}$ [43]. Similarly, the O 1s core levels XPS spectra under Al K $\alpha$ irradiation were fitted with Gaussian functions. In the present work, the $\mathrm{MgO} O \mathrm{O}$ s peaks are at $530.02 \mathrm{eV}(\mathrm{Al}-2 \mathrm{Mg}$ $R l)$ and $530.01 \mathrm{eV}(A l-2 M g-R l)$ and the $\mathrm{Mg}(\mathrm{OH})_{2} \mathrm{O} 1 \mathrm{~s}$ peaks are at $532.16 \mathrm{eV}(A l-2 M g-R \sigma)$ and $532.15 \mathrm{eV}(A l-2 M g-R \sigma)$. It can be seen that fitted $\mathrm{MgO} \mathrm{O}$ 1s peaks are all located at a spectral line of $530.00 \pm 0.02 \mathrm{eV}$ and $\mathrm{Mg}(\mathrm{OH})_{2} \mathrm{O}$ 1s peaks are all located at a spectral line of $532.20 \pm 0.05 \mathrm{eV}$. The results clearly prove the presence of only $\mathrm{MgO}$ at the top surface (at least first $10 \mathrm{~nm}$ range) of $A l-2 M g-R I$ and $A l-2 M g-R 6$. Whilst, only $\mathrm{Al}_{2} \mathrm{O}_{3}$ is identified in the $A l-2 M g$-AP sample with the $\mathrm{O} 1 \mathrm{~s}$ peak located in the range $532.65 \pm 0.05 \mathrm{eV}$, suggesting the first naturally formed oxide layer on solid Al-2Mg alloy is aluminium oxide. At the same time, since the energy of $\mathrm{Al} \mathrm{K} \alpha \mathrm{X}$-rays is higher than $\mathrm{Mg} \mathrm{K} \alpha$ Xrays, Al $\mathrm{K} \alpha \mathrm{X}$-rays generate information from a greater sample depth than $\mathrm{Mg} \mathrm{K \alpha}$ X-rays, the ratio of $\mathrm{MgO} / \mathrm{Mg}(\mathrm{OH})_{2}$ quantified from the spectra varies with the energy of X-ray used. From the data in Figure 4(d), the intensity ratio for $\mathrm{MgO}$ and $\mathrm{Mg}(\mathrm{OH})_{2}$ changes from 1:2.01 to 1:1.78 for sample $\mathrm{Al}-2 \mathrm{Mg}$ $R 1$. Similarly, the ratio changes from 1:1.98 to 1:1.45 for sample Al-2Mg-R6.

It can be seen from the above results that aluminium oxide on an $\mathrm{Al}-2 \mathrm{Mg}$ sample transforms to $\mathrm{MgO}$ in the external part of the oxide scale during oxidation of a liquid alloy. Similarly, Lea and Ball [25,27] found that aluminium oxide initially formed on an $\mathrm{Al}-2.5 \mathrm{Mg}$ alloy, and $\mathrm{MgO}$ entirely covered the surface after $1 \mathrm{~h}$ oxidation at $600^{\circ} \mathrm{C}$ i.e. solid state oxidation.

\section{(c) $M g$ 2p}

$\mathrm{Mg} 2 \mathrm{p}$ core levels were also analysed to confirm the presence of $\mathrm{MgO}$ on $A l-2 M g-R I$ and $A l$ $2 M g$ - $R 6$. As shown in Figure 4(e), Mg 2p peaks are all located within the range $51.2 \pm 0.2 \mathrm{eV}$ and broad peaks at higher binding energies of $53.5 \pm 0.5 \mathrm{eV}$ are attributed to $\mathrm{Mg}(\mathrm{OH})_{2}$. The width of, and intensities under, the $\mathrm{Mg}(\mathrm{OH})_{2} \mathrm{Mg} 2 \mathrm{p}$ peaks may be related to the levels of hydration. The absence of $\mathrm{Mg} 2 \mathrm{p}$ peaks for $A l-2 M g-A P$ is due to the formation of aluminium oxide instead of $\mathrm{MgO}$, this is consistent with previous results and also the work by Panda et al. $[43,53,54]$ who found the absence of the $\mathrm{Mg} 2 \mathrm{p}$ signal from an $\mathrm{Al}-1.1 \mathrm{Mg}$ sample which was oxidized in pure oxygen at $400 \mathrm{~K}$ for $6000 \mathrm{~s}$. Panda et al. [39] proposed a complex thermodynamic model to show that amorphous $\gamma-\mathrm{Al}_{2} \mathrm{O}_{3}$ is more thermodynamically favourable than amorphous $\mathrm{MgO}$ or amorphous $\mathrm{MgAl}_{2} \mathrm{O}_{4}$ on the $\mathrm{Al}-\mathrm{Mg}$ substrate (at least $0-50 \% \mathrm{Mg}$ ) for temperatures below $610 \mathrm{~K}$ (i.e. in the solid state) due to its lower interfacial energy with the $\mathrm{Al}-\mathrm{Mg}$ metal substrate, further suggesting the preferential formation of $\mathrm{Al}_{2} \mathrm{O}_{3}$ at the early stage of oxidation. To sum up, based on previous results and discussion, it may be reasonably concluded that (1) the as-polished $\mathrm{Al}-2 \mathrm{Mg}$ alloy is naturally covered with an aluminium oxide 
layer with a thickness of around $5 \mathrm{~nm}$ at room temperature; (2) $\mathrm{MgO}$ is essentially present in the external part of the oxide film thermally grown on liquid $\mathrm{Al}-2 \mathrm{Mg}$ samples and it is prone to hydration.

\subsection{Kinetics of oxidation}

The TGA results indicate that the oxidation kinetics of Al-Mg alloys are affected by both oxidizing temperature and alloy composition. Figures $5(\mathrm{a} \& \mathrm{~b})$ show the oxidation kinetics curves of $\mathrm{Al}-0.2 \mathrm{Mg}$ and $\mathrm{Al}-2 \mathrm{Mg}$ (note the different scales on $\mathrm{Y}$ axis). It can be seen that there is a linear-like behaviour in the temperature range of $750-950^{\circ} \mathrm{C}$, particularly in the later stage of oxidation (approximately after 600 seconds). This may suggest that there are some nonprotective characteristics of the oxide scale. In this temperature range, the alloys are in the liquid state. In the temperature range of $450-650^{\circ} \mathrm{C}$, the oxidation growth also shows linear progression in the later stage (approximately after 2400 seconds). However, for both alloys, parabolic-like behaviour is observed during the earlier stage of oxidation (before 600s), probably indicating some degree of protectiveness of the initially formed oxide structure.

The overall oxidation kinetics of Al-Mg alloys may be best described by a para-linear growth law: the initial stage shows a parabolic-like progression and then the oxidation gradually progresses linearly. Similar behaviour was observed by Lea and Ball [40] who found that an $\mathrm{Al}-2.5 \mathrm{Mg}$ alloy exhibited a para-linear growth rate $(1 \mathrm{~h}$ time, dry air $)$ at $500^{\circ} \mathrm{C}$. The oxidation rate for $\mathrm{Al}-2 \mathrm{Mg}$ is faster than that for $\mathrm{Al}-0.2 \mathrm{Mg}$ at all temperatures, suggesting the accelerating effect of $\mathrm{Mg}$ on the oxidation of $\mathrm{Al}$. The weight gain curves as a function of time between 2400s and 3600s were fitted linearly and plotted using Arrhenius equations to estimate the oxidation activation energy. The results are summarized in Table 1.

From Figure 5(c), it is noted that the Arrhenius plots for both $\mathrm{Al}-0.2 \mathrm{Mg}$ and $\mathrm{Al}-2 \mathrm{Mg}$ (less obvious) consist of two parts, having two different activation energies. This clearly suggests a kinetic advantage for liquid state oxidation. Similar results were reported by Tenorio and Espinosa [23], and Jin et al. [41] who also estimated the activation energy to be around 50-100 $\mathrm{kJ} \mathrm{mol}^{-1}$ using a modified Chou model [42].

As shown by the TGA results, in the later stage of oxidation (after 2400s), the weight gain curves for $\mathrm{Al}-0.2 \mathrm{Mg}$ and $\mathrm{Al}-2 \mathrm{Mg}$ are almost linear, indicating the rate-controlling process may be the reaction between $\mathrm{Mg}$ and $\mathrm{O}_{2}$, rather than the diffusion of any species [43], as both $\mathrm{Mg}$ and $\mathrm{O}_{2}$ may easily flow through the porously structured oxide scale. 
For $\mathrm{Al}-0.2 \mathrm{Mg}$, the oxidation rate equations in the temperature range of $450-650^{\circ} \mathrm{C}$ and $750-$ $950^{\circ} \mathrm{C}$ are given by

$R_{A l-0.2 \mathrm{Mg}}=3.6 \times 10^{-3} \exp \left[-\frac{63900}{R T}\right]$ (Linear stage, $450-650^{\circ} \mathrm{C}, \mathrm{mg} \mathrm{cm}^{-2} \mathrm{~s}^{-1}$ ) Equation (1)

$R_{A l-0.2 \mathrm{Mg}}=1.2 \times 10^{-3} \exp \left[-\frac{53500}{R T}\right]$ (Linear stage, $750-950^{\circ} \mathrm{C}, \mathrm{mg} \mathrm{cm}^{-2} \mathrm{~s}^{-1}$ ) Equation (2)

For $\mathrm{Al}-2 \mathrm{Mg}$, the oxidation rate equations in the temperature range of $450-650^{\circ} \mathrm{C}$ and $750-$ $950^{\circ} \mathrm{C}$ are calculated as

$R_{A l-2 M g}=0.53 \exp \left[-\frac{85400}{R T}\right]$ (Linear stage, $450-650^{\circ} \mathrm{C}, \mathrm{mg} \mathrm{cm}^{-2} \mathrm{~s}^{-1}$ ) Equation (3)

$R_{A l-2 M g}=1.3 \times 10^{-3} \exp \left[\frac{37200}{R T}\right]\left(\right.$ Linear stage, $\left.750-950^{\circ} \mathrm{C}, \mathrm{mg} \mathrm{cm}^{-2} \mathrm{~s}^{-1}\right) \quad$ Equation (4)

\subsection{Thermodynamic calculations}

The following is a list of all possible chemical reactions in the Al- $\mathrm{Mg}-\mathrm{O}_{2}$ system [44-46]. It can be seen that $\mathrm{MgO}$ may form from either a direct reaction between $\mathrm{Mg}$ and $\mathrm{O}_{2}$ or through a reduction reaction between $\mathrm{Mg}$ and $\mathrm{Al}_{2} \mathrm{O}_{3}$, and $\mathrm{MgO}$ to $\mathrm{MgAl}_{2} \mathrm{O}_{4}$ transformation can take place with the presence of $\mathrm{Al}$ or $\mathrm{Al}_{2} \mathrm{O}_{3}$.

$$
\begin{array}{ll}
2 \mathrm{Mg}(s, l, g)+\mathrm{O}_{2}(g) \rightarrow 2 \mathrm{MgO}(s) & \text { Reaction (1) } \\
4 / 3 \mathrm{Al}(s, I)+\mathrm{O}_{2}(g) \rightarrow 2 / 3 \mathrm{Al}_{2} \mathrm{O}_{3}(s) & \text { Reaction (2) } \\
1 / 2 \mathrm{Mg}(s, l, g)+\mathrm{Al}(s, I)+\mathrm{O}_{2}(g) \rightarrow 1 / 2 \mathrm{MgAl}_{2} \mathrm{O}_{4}(s) & \text { Reaction (3) } \\
3 \mathrm{Mg}(s, l, g)+\mathrm{Al}_{2} \mathrm{O}_{3}(s) \rightarrow 3 \mathrm{MgO}(s)+2 \mathrm{Al}(s, I) & \text { Reaction (4) } \\
\operatorname{MgO}(s)+2 \mathrm{Al}(s, I)+3 / 2 \mathrm{O}_{2}(g) \rightarrow \mathrm{MgAl}_{2} \mathrm{O}_{4}(s) & \text { Reaction (5) } \\
\operatorname{MgO}(s)+\mathrm{Al}_{2} \mathrm{O}_{3}(s) \rightarrow \mathrm{MgAl}_{2} \mathrm{O}_{4}(s) & \text { Reaction (6) }
\end{array}
$$

\section{Gibbs free energy functions}

The standard free energy change associated with each of the above reactions as a function of temperature (unit: $\mathrm{J} \mathrm{mol}^{-1}$ ) can be calculated for temperatures in the range 300-1300 K (27$1027^{\circ} \mathrm{C}$ ). The equations have been explained in appendix A of Part I of this work. The standard 
free energy data for all elements and compounds used in this work has been tabulated in Table 2 and 3 .

$\Delta G^{\circ}{ }_{1}(T)=-1193268+95.68 \mathrm{~T}+16.28 \mathrm{~T} \ln \mathrm{T}$

Equation (5)

$\Delta G_{2}^{\circ}(\mathrm{T})=-1099621+148.60 \mathrm{~T}+7.82 \mathrm{~T} \ln \mathrm{T}$

Equation (6)

$\Delta G^{\circ}{ }_{3}(\mathrm{~T})=-1142545+110.10 \mathrm{~T}+12.98 \mathrm{~T} \ln \mathrm{T}$

Equation (7)

$\Delta G^{\circ}{ }_{4}(\mathrm{~T})=-123433-43.84 \mathrm{~T}+7.25 \mathrm{~T} \ln \mathrm{T}$

Equation (8)

$\Delta G^{\circ}{ }_{5}(\mathrm{~T})=-1688560+172.35 \mathrm{~T}+17.83 \mathrm{~T} \ln \mathrm{T}$

Equation (9)

$\Delta G^{\circ}{ }_{6}(\mathrm{~T})=-22086-15.01 \mathrm{~T}+0.66 \mathrm{~T} \ln \mathrm{T}$

Equation (10)

In practice, the reactants are not always at standard state and they are normally dissolved in solution, so the chemical activities of different phases must be taken into consideration.

Equations 5-10 are therefore modified to

$$
\begin{aligned}
& \Delta G_{1}(T)=\Delta G^{\circ}(T)+R T \ln \left[\frac{a_{M g O}^{2}}{a_{M g}^{2} P_{O_{2}}}\right] \\
& \Delta G_{2}(T)=\Delta G^{\circ}(T)+R T \ln \left[\frac{a_{A l_{2} O_{3}}^{2 / 3}}{a_{A l}^{4 / 3} P_{O_{2}}}\right] \\
& \Delta G_{3}(T)=\Delta G^{\circ}(T)+R T \ln \left[\frac{a_{M g A l_{2} O_{4}}^{1 / 2}}{a_{M g}^{1 / 2} a_{A l} P_{O_{2}}}\right] \\
& \Delta G_{4}(T)=\Delta G^{\circ}(T)+R T \ln \left[\frac{a_{M g O}^{3} a_{A l}^{2}}{a_{M g}^{3} a_{A l_{2} O_{3}}}\right] \\
& \Delta G_{5}(T)=\Delta G^{\circ}(T)+R T \ln \left[\frac{a_{M g A l_{2} O_{4}}}{a_{M g O} a_{A l}^{2} P_{O_{2}}^{3 / 2}}\right] \\
& \Delta G_{6}(T)=\Delta G^{\circ}(T)+R T \ln \left[\frac{a_{M g A l_{2} O_{4}}}{a_{M g O} a_{A l_{2} O_{3}}}\right]
\end{aligned}
$$

Equation (16)

According to previous results and discussion, the oxidation mechanism of molten Al-Mg alloys is suggested as follows: the Al-Mg melt is initially covered by an amorphous $\mathrm{Al}_{2} \mathrm{O}_{3}$ skin; $\mathrm{MgO}$ particles then form through a direct reaction mechanism between inwardly diffusing oxygen molecules and $\mathrm{Mg}$ gas molecules, as well as a reduction reaction mechanism between the dissolved $\mathrm{Mg}$ in the amorphous structure and the oxygen from the initially formed $\mathrm{Al}_{2} \mathrm{O}_{3}$; the depletion of $\mathrm{Mg}$ favours the growth of $\mathrm{MgAl}_{2} \mathrm{O}_{4}$ at later stages of oxidation. 
First of all, assuming the oxygen gas behaves ideally, the partial pressure of oxygen in air is therefore proportional to its fraction, which is around 0.21 atm (Note: $P_{\mathrm{O}_{2}}$ is used as an expression for $a_{\mathrm{O}_{2}}$ throughout further discussion). In fact, the $\mathrm{Al}$ or $\mathrm{Mg}$ would theoretically react with all gas phases present, e.g. reacting with nitrogen to form nitrides [47], but the amount of reduction in Gibbs free energy of these metal-gas reactions are approximately one order of magnitude smaller than those of the metal-oxygen reactions, making them thermodynamically less favourable and negligible when oxygen is readily available $[47,48]$. Secondly, as it has been suggested by Alper et al. [47], Salas et al. [48] and Valdez et al. [49] that $\mathrm{Al}_{2} \mathrm{O}_{3}, \mathrm{MgO}$ and $\mathrm{MgAl}_{2} \mathrm{O}_{4}$ are nearly immiscible in each other in the temperature range $25-1000^{\circ} \mathrm{C}$, the chemical activities of these oxides are therefore assumed equal to 1 throughout the analysis. Thirdly, according to the classical principles of thermodynamics [50-53], the chemical activity of $\mathrm{Mg}$ is given by

$$
a_{M g}=\gamma \cdot X_{M g}
$$

Equation (17)

Where $\gamma$ is the activity coefficient and $X_{\mathrm{Mg}}$ is the mole fraction of $\mathrm{Mg}$ in the system. The activity coefficient $\gamma$ as a function of time and temperature is quoted from Tiwari [53] as

$$
\ln \gamma_{M g}=\frac{222.52}{T}\left(1-X_{M g}\right)^{2}+0.4016\left(1-\frac{1073.15}{T}\right)
$$

Figure 6(a) is a plot based on Equations 17 and 18, showing the $\mathrm{Mg}$ chemical activity as a function of $\mathrm{Mg}$ composition at different temperatures. It can be noted that at $25^{\circ} \mathrm{C}$, the activity coefficient $\gamma$ is less than 0.5 , and then gradually approaches 1 as the temperature increases. Meanwhile, the results from Murray [55], Bhatt and Garg [56], and Saunders [57] have suggested that the $\mathrm{Al}$ chemical activity in the $\mathrm{Al}-\mathrm{Mg}$ system can be approximated as ideal and can be calculated using Raoult's law [58].

$$
a_{A l}=X_{A l}=1-X_{M g}
$$

Bringing Equations 11-16 and 17-19 together, it is inferred that $\Delta G$ is a function of $\mathrm{Mg}$ 
composition and temperature which can be represented by

$\Delta G=\Delta G\left(X_{M g}, T\right)$

Equation (20)

In the present work, $\Delta G$ plots are used to understand which oxide is the most thermodynamically favourable at different combinations of $\mathrm{Mg}$ composition and temperature.

\section{Mg vapour pressure}

It has been shown by Bloch et al. [59] that $\mathrm{Mg}$ can vaporize into individual $\mathrm{Mg}$ molecules at temperatures above $200^{\circ} \mathrm{C}$. The presence of the $\mathrm{Mg}$ gas phase could enhance the $\mathrm{Mg}$ chemical activity and change the thermodynamics locally. It is therefore necessary to know the $\mathrm{Mg}$ vapour pressure at different temperatures. The vapour pressure of $\mathrm{Mg}$ can be calculated using the function of Gibbs free energy change of the following reaction

$$
\operatorname{Mg}(s, l) \rightarrow \operatorname{Mg}(g) \quad \text { Reaction (7) }
$$

The function of Gibbs free energy change (unit: $\mathrm{J} \mathrm{mol}^{-1}$ ) for this reaction is calculated as

$\Delta G^{o}(T)=155860-253.40 T+19.20 T \ln T$

Equation (21)

$\Delta G(T)=\Delta G^{o}(T)+R T \ln \frac{P_{M g}}{P^{o}}$

Equation (22)

where $P_{\mathrm{Mg}}$ is the $\mathrm{Mg}$ vapour pressure and $P^{o}$ is the reference pressure (atmospheric pressure in this case).

When $\Delta G=0$, Reaction 7 reaches an equilibrium and Equation 22 is modified to

$\ln \frac{P_{M g}}{P^{o}}=-\frac{18747}{T}-2.31 \ln T+30.48$

Equation (23) 
Figure 6(b) is a plot constructed using Equation 23, showing the Mg vapour pressure as a function of temperature in the range $300-1300 \mathrm{~K}\left(27-1027^{\circ} \mathrm{C}\right)$. In the present work, using the above method, it is estimated that $\mathrm{Mg}$ has a high vapour pressure up to more than $2.14 \mathrm{kPa}$ at $750^{\circ} \mathrm{C}$ while the vapour pressure of $\mathrm{Al}$ is only around $0.14 \mathrm{kPa}$. So it is reasonable to assume that the influence of the Al gas phase is negligible in such a system. A similar suggestion was also made by Damoah et al. [58].

\section{Effect of Mg composition}

Previously in the literature, Haginoya and Fukusako [21], and Ritchie et al. [20] have attempted to explain their observations of $\mathrm{MgO}$ and $\mathrm{MgAl}_{2} \mathrm{O}_{4}$ in the oxide scales from a perspective of thermodynamics. But they did not take the chemical activities of $\mathrm{Mg}, \mathrm{Al}$ and $\mathrm{O}_{2}$ into consideration and simply used the standard Gibbs free energy change of each reaction to compare thermodynamic tendencies. In the present work, Equations 11-13 are therefore plotted to understand which oxide is the most thermodynamically stable at different combinations of Mg composition and temperature. Figure 6(c) shows the Gibbs free energy change profiles of the oxides $\mathrm{Al}_{2} \mathrm{O}_{3}, \mathrm{MgAl}_{2} \mathrm{O}_{4}$ and $\mathrm{MgO}$ as a function of $X_{\mathrm{Mg}}$ at $950^{\circ} \mathrm{C}$. Similar plots were constructed from $25-950^{\circ} \mathrm{C}$ but are not presented in the interest of brevity.

First of all, it can be seen that $\mathrm{MgO}$ becomes the most favourable once in excess of a critical $\mathrm{Mg}$ composition (defined as $C_{\mathrm{Mg}}$ ) and $\mathrm{MgAl}_{2} \mathrm{O}_{4}$ becomes the most favourable below this critical $\mathrm{Mg}$ composition (highlighted by the green dashed lines). $\mathrm{Al}_{2} \mathrm{O}_{3}$ becomes the most favourable when the $\mathrm{Mg}$ mole fraction is below at least 0.02 (highlighted by the purple dashed line). The critical $\mathrm{Mg}$ composition $C_{\mathrm{Mg}}$ (mole fraction) at different temperatures is shown in Table 4. It is noted that $C_{\mathrm{Mg}}$ increases with temperature, as shown in Figure 6(d).

Below $400^{\circ} \mathrm{C}, C_{\mathrm{Mg}}$ does not vary very much with increasing temperature and it is less than 0.01 . Above $400^{\circ} \mathrm{C}, C_{\mathrm{Mg}}$ increases approximately linearly with temperature, suggesting an increased thermodynamic favourability of $\mathrm{MgAl}_{2} \mathrm{O}_{4}$ at high temperatures. The results also suggest that $\mathrm{MgO}$ is the most favourable oxide when the $\mathrm{Mg}$ mole fraction is more than 0.01 in the temperature range $25-950^{\circ} \mathrm{C}$. This is consistent with the observations reported by Wakefield and Sharp [18] that oxide formed at $430^{\circ} \mathrm{C}$ in an Al-10 wt.\% $\mathrm{Mg}$ alloy consists of almost entirely $\mathrm{MgO}$. 


\subsection{Growth Behaviour}

\section{Mg segregation and evaporation}

Oxidation studies of the $\mathrm{Al}-\mathrm{Mg}-\mathrm{O}_{2}$ system are more complicated than other systems. First, $\mathrm{Mg}$ atoms readily segregate at the surface through rapid grain boundary diffusion especially at temperatures above $200^{\circ} \mathrm{C}$ [60]. It has been shown that the level of $\mathrm{Mg}$ at the surface could be increased to 35 at\% for an Al- $0.005 \mathrm{Mg}$ alloy at $800^{\circ} \mathrm{C}$ [61]. Secondly, $\mathrm{Mg}$ has a high vapour pressure. The evaporation of $\mathrm{Mg}$ could lead to the loss of $\mathrm{Mg}$ and the direct reaction between $\mathrm{Mg}$ gas phase and oxygen. This causes depletion of $\mathrm{Mg}$ and may influence the surface $\mathrm{Mg}$ content to an unknown extent.

Thermodynamically, it has been shown that $\mathrm{Mg}$ atoms segregate to free surfaces or grain boundaries as an attempt to reduce the free energy of the system [62-65]. Meanwhile, the presence of large solute atoms (Mg atom 12\% larger than $\mathrm{Al}$ atom) sets up a strain field in the bulk and it can be relieved by $\mathrm{Mg}$ atoms sitting at a free surface, where the coordination number is low and there is excess free volume [66-68]. So the size effect provides another driving force for $\mathrm{Mg}$ to segregate to the surface in Al-Mg alloys. Kinetically, some researchers believe that the surface segregation of $\mathrm{Mg}$ is mainly due to the fast diffusivity of $\mathrm{Mg}$ along the grain boundaries of $\alpha-\mathrm{Al}$ in the solid state and $\mathrm{Mg}$ atoms are rapidly delivered to the free surface via these paths [63]. It has been shown by the Langmuir-Mclean theory that the segregation kinetics can be described by an Arrhenius type equation in terms of segregation energy

$\frac{x_{s}}{1-x_{s}}=\frac{x_{b}}{1-x_{b}} \exp \left(-\frac{G}{R T}\right)$

Equation (24)

where $x_{s}$ refers to the equilibrium solute composition in the surface region (a few atomic layers) and $x_{b}$ refers to the equilibrium solute composition in the bulk, and $G$ is the free energy of segregation. If the segregation energy is positive, then solute atoms segregate at the free surface to reduce the total Gibbs free energy, and vice versa. The exponential term is usually regarded as an enrichment ratio, which is predicted to be around 1-10 in the case of Al-Mg alloys [63]. However, this equation may only be applied to solid state segregation and there is currently no widely accepted segregation theory for liquid metal, and it could be far more complicated than a simple equation can explain. Even if Equation 24 is correct, the segregation free energy still 
needs to be determined, which is expected to be approximately $20-50 \mathrm{~kJ} \mathrm{~mol}^{-1}$ [15]. But it is likely that there is already some degree of $\mathrm{Mg}$ segregation occurring during the heating up period when the Al-Mg is still in the solid state.

\section{Conclusions}

The oxidation of $\mathrm{Al}-\mathrm{Mg}$ alloys shows strong preferential oxidation of $\mathrm{Mg}$ into $\mathrm{MgO}$ and $\mathrm{MgAl}_{2} \mathrm{O}_{4}$ in the oxide scale. The addition of $\mathrm{Mg}$ to $\mathrm{Al}$ will prevent the formation of aluminium oxide thermodynamically. Following the initially formed amorphous aluminium oxide layer, $\mathrm{MgO}$ is usually the second oxide appearing in the scale. Further oxidation causes the depletion of $\mathrm{Mg}$ and the formation of $\mathrm{MgAl}_{2} \mathrm{O}_{4}$ dominates over $\mathrm{MgO}$. Kinetically, the oxidation is rationalized by paralinear laws. Microscopically, during the initial stage of oxidation, the morphology of the oxide layer develops from an early compact and protective uniform amorphous layer to a loosely structured oxide scale with agglomerates of $\mathrm{MgO}$ particles. The outer surface of the atmospherically oxidized Al-2Mg alloy is covered entirely by $\mathrm{MgO}$ as confirmed by XPS studies. For low composition alloys $\mathrm{MgAl}_{2} \mathrm{O}_{4}$ is thermodynamically more stable than $\mathrm{MgO}$, but $\mathrm{MgO}$ forms before $\mathrm{MgAl}_{2} \mathrm{O}_{4}$. The paralinear kinetic law suggests that the formation of $\mathrm{MgO}$ occurs when the oxidation kinetics are parabolic in nature and $\mathrm{MgAl}_{2} \mathrm{O}_{4}$ forms during the linear stage of oxidation after $\mathrm{MgO}$ has formed. Thus, we can say that $\mathrm{MgAl}_{2} \mathrm{O}_{4}$ is not a protective oxide.

\section{Acknowledgement}

The authors would like to thank Department of Materials, University of Oxford for all the infrastructural and research support.

\section{Data availability}

The raw/processed data required to reproduce these findings cannot be shared at this time as the data also forms part of an ongoing study. 


\section{References}

[1] H.J. van Beek, E.J. Mittemeijer, Amorphous and crystalline oxides on aluminium, Thin Solid Films. 122 (1984) 131-151. doi:https://doi.org/10.1016/0040-6090(84)90004-X.

[2] K. Shimizu, G.M. Brown, K. Kobayashi, P. Skeldon, G.E. Thompson, G.C. Wood, The early stages of high temperature oxidation of an Al-0.5wt\% Mg alloy, Corros. Sci. 40 (1998) 557-575. doi:10.1016/S0010-938X(97)00153-4.

[3] L.P.H. Jeurgens, W.G. Sloof, F.D. Tichelaar, E.J. Mittemeijer, Structure and morphology of aluminium-oxide films formed by thermal oxidation of aluminium, Thin Solid Films. 418 (2002) 89-101. doi:10.1016/S0040-6090(02)00787-3

[4] L.P.H. Jeurgens, W.G. Sloof, F.D. Tichelaar, E.J. Mittemeijer, Growth kinetics and mechanisms of aluminum-oxide films formed by thermal oxidation of aluminum, J. Appl. Phys. 92 (2002) 1649-1656. doi:10.1063/1.1491591.

[5] F. Gronlund, J. Chim. 53 doi:https://doi.org/10.1051/jcp/1956530660

(1956)

[6] F. Grønlund, P.J. Møller, Nucleation control in metal surface oxidation, Surf. Sci. 184 (1987) 530-540. doi:https://doi.org/10.1016/S0039-6028(87)80373-4.

[7] C.T. Rettner, M.N.R. Ashfold, Dynamics of gas-surface interactions, Royal Society of Chemistry, $100 \quad$ (1991) 13021-13033. https://books.google.co.in/books?id=p6vvAAAAMAAJ.

[8] C.T. Rettner, D.J. Auerbach, J.C. Tully, A.W. Kleyn, Chemical dynamics at the gassurface interface, J. Phys. Chem. 100 (1996) 13021-13033. doi:10.1021/jp9536007.

[9] P.E. Doherty, R.S. Davis, Direct observation of the oxidation of aluminum singlecrystal surfaces, J. Appl. Phys. 34 (1963) 619-628. doi:10.1063/1.1729318.

[10] J.I. Eldridge, R.J. Hussey, D.F. Mitchell, M.J. Graham, Thermal oxidation of singlecrystal aluminum at $550^{\circ} \mathrm{C}$, Oxid. Met. 30 (1988) 301-328. doi:10.1007/BF00659003.

[11] K. Shimizu, R.C. Furneaux, G.E. Thompson, G.C. Wood, A. Gotoh, K. Kobayashi, On the nature of "easy paths" for the diffusion of oxygen in thermal oxide films on aluminum, Oxid. Met. 35 (1991) 427-439. doi:10.1007/BF00664713.

[12] K. Shimizu, The Nucleation Sites of Gamma-Al2O3 Crystals in Thermal Oxide-Films on Aluminum, in: Microsc. Oxid., 1992: pp. 144-148.

[13] R. Kiusalaas, L. Backerud, Solidification processing, Solidification Characteristics of Aluminum Alloys. Vol. 2. Foundry Alloys. American Foundrymen's Society, Inc., 1990, 1990: p. 266.

[14] J. Campbell, Rule 3 - Avoid laminar entrainment of the surface film (the non-stopping, non-reversing condition), in: J. Campbell (Ed.), Cast. Pract., Butterworth-Heinemann, Oxford, 2004: pp. 102-107. doi:https://doi.org/10.1016/B978-075064791-5/50004-9.

[15] L.F. Mondolfo, Aluminum alloys: structure and properties, Butterworth-Heinemann, 1976. doi:https://doi.org/10.1016/C2013-0-04239-9.

[16] D.R. Lide, CRC Handbook of Chemistry and Physics, CRC, 1914.

[17] D.J. Field, G.M. Scamans, E.P. Butler, The high temperature oxidation of Al-4.2 Wt Pct Mg alloy, Metall. Trans. A. 18 (1987) 463-472. doi:10.1007/BF02648807.

[18] G.R. Wakefield, R.M. Sharp, The composition of oxides formed on Al-Mg alloys, Appl. Surf. Sci. 51 (1991) 95-102. doi:10.1016/0169-4332(91)90065-R.

[19] A. Bahadur, Behaviour of Al-Mg alloys at high temperature, J. Mater. Sci. 22 (1987) 1941-1944. doi:10.1007/BF01132920. 
[20] I.M. Ritchie, J. V. Sanders, P.L. Weickhardt, Oxidation of a dilute aluminum magnesium alloy, Oxid. Met. 3 (1971) 91-101. doi:10.1007/BF00604741.

[21] I. Haginoya, T. Fukusako, Oxidation of Molten Al-Mg Alloys, Trans. Japan Inst. Met. 24 (1983) 613-619. doi:10.2320/matertrans 1960.24.613.

[22] H. Venugopalan, T. DebRoy, Growth stage kinetics in the synthesis of $\mathrm{Al}_{2} \mathrm{O}_{3} / \mathrm{Al}$ composites by directed oxidation of Al-Mg and Al-Mg-Si alloys, J. Eur. Ceram. Soc. 16 (1996) 1351-1363. doi:https://doi.org/10.1016/0955-2219(96)00068-4.

[23] J.A.S. Tenório, D.C.R. Espinosa, High-Temperature Oxidation of Al--Mg Alloys, Oxid. Met. 53 (2000) 361-373. doi:10.1023/A:1004549522648.

[24] K. Surla, F. Valdivieso, M. Pijolat, M. Soustelle, M. Prin, Kinetic study of the oxidation by oxygen of liquid Al-Mg 5\% alloys, Solid State Ionics. 143 (2001) 355365. doi:https://doi.org/10.1016/S0167-2738(01)00861-X.

[25] C. Lea, C. Molinari, Magnesium diffusion, surface segregation and oxidation in AlMg alloys, J. Mater. Sci. 19 (1984) 2336-2352. doi:10.1007/BF01058110.

[26] A. Kanti De, A. Mukhopadhyay, S. Sen, I.K. Puri, Numerical simulation of early stages of oxide formation in molten aluminium-magnesium alloys in a reverberatory furnace, Model. Simul. Mater. Sci. Eng. 12 (2004) 389-405. doi:10.1088/09650393/12/3/003.

[27] C. Lea, J. Ball, The oxidation of rolled and heat treated Al-Mg alloys, Appl. Surf. Sci. 17 (1984) 344-362. doi:10.1016/0378-5963(84)90023-0.

[28] Y. Yoon, S. Ha, S.K. Kim, Pilling-Bedworth ratio approach to surface oxidation of Al$\mathrm{Mg}$ alloys with $\mathrm{Al}_{2} \mathrm{Ca}$ and its experimental verification, 3 (2016) 231-235 .

[29] S.-H. Ha, Y.-O. Yoon, B.-H. Kim, T.-W. Lee, S.-H. Lim, S.K. Kim, Precipitation of Oxide Particles in Surface Mixed Layer of Al-Mg Alloys with a Trace of Ca During Oxidation, J. Nanosci. Nanotechnol. $17 \quad$ (2017) 8232-8235. doi:10.1166/jnn.2017.15104.

[30] B.-H. Kim, S.-H. Ha, Y.-O. Yoon, H.-K. Lim, S.K. Kim, D.-H. Kim, Effect of Ca addition on selective oxidation of $\mathrm{Al}_{3} \mathrm{Mg}_{2}$ phase in Al-5 mass $\% \mathrm{Mg}$ alloy, Mater. Lett. 228 (2018) 108-111. doi:10.1016/j.matlet.2018.05.132.

[31] T. Hiraki, H. Noguchi, N. Maruoka, T. Nagasaka, In Situ Observation of Dross Formation During Melting of Al-Mg Alloy, Miner. Met. Mater. Ser. Part F4 (2018) 1141-1146. doi:10.1007/978-3-319-72284-9_149.

[32] S. Ha, Y. Yoon, B. Kim, H. Lim, S.K. Kim, Oxide scale behavior and surface protection of Al-Mg alloys containing a trace of $\mathrm{Ca}$, (2018) 1-9.

[33] Rabald, Oxidation of metals and alloys. Von O. Kubaschewski und B. E. Hopkins. London: Butterworths Scientific Publications 1953. Mater. Corros. 5 (1953) 477. doi:10.1002/maco.19540051125.

[34] J. Campbell, Entrainment defects, Mater. Sci. Technol. 22 (2006) 127-145. doi:10.1179/174328406X74248.

[35] N. Birks, G.H. Meier, F.S. Pettit, Introduction to the High Temperature Oxidation of Metals, 2006. doi:10.2277/0521480426.

[36] J.I. Eldridge, R.J. Hussey, D.F. Mitchell, M.J. Graham, Thermal oxidation of singlecrystal aluminum at $550^{\circ} \mathrm{C}$, Oxid. Met. 30 (1988) 301-328. doi:10.1007/BF00659003.

[37] E. Panda, L.P.H. Jeurgens, E.J. Mittemeijer, The initial oxidation of Al-Mg alloys: Depth-resolved quantitative analysis by angle-resolved x-ray photoelectron spectroscopy and real-time in situ ellipsometry, J. Appl. Phys. 106 (2009). doi:10.1063/1.3268480. 
[38] E. Panda, L.P.H. Jeurgens, G. Richter, E.J. Mittemeijer, The amorphous to crystalline transition of ultrathin ( $\mathrm{Al}, \mathrm{Mg}$ )-oxide films grown by thermal oxidation of $\mathrm{AlMg}$ alloys: A high-resolution transmission electron microscopy investigation, J. Mater. Res. 25 (2010) 871-879. doi:10.1557/JMR.2010.0110.

[39] J.A.S. Tenório, D.C.R. Espinosa, High-Temperature Oxidation of Al--Mg Alloys, Oxid. Met. 53 (2000) 361-373. doi:10.1023/A:1004549522648.

[40] F. Jin, Q. Luo, B. Zhou, Q. Li, Modeling Investigation of the Oxidation Kinetics of Copper and Aluminum Alloys, in: Adv. Metall. Min. Eng., Trans Tech Publications, 402 (2012) 17-21. doi:10.4028/www.scientific.net/AMR.402.17.

[41] K.C. Chou, A kinetic model for oxidation of Si-Al-O-N materials, J. Am. Ceram. Soc. 89 (2006) 1568-1576. doi:10.1111/j.1551-2916.2006.00959.x.

[42] D.A. Weirauch, Interfacial phenomena involving liquid metals and solid oxides in the Mg-Al-O system, J. Mater. Res. 3 (1988) 729-739. doi:10.1557/JMR.1988.0729.

[43] D.G. Kim, J. Kaneko, M. Sugamata, Preferential oxidation of Mg in mechanically alloyed Al-Mg-O based systems, Mater. Trans. JIM. 36 (1995) 305-311. doi:10.2320/matertrans1989.36.305.

[44] R. Raiszadeh, W.D. Griffiths, A method to study the history of a double oxide film defect in liquid aluminum alloys, Metall. Mater. Trans. B 37 (2006) 865-871. doi:10.1007/BF02735007.

[45] N. Birks, G.H. Meier, F.S. Pettit, Introduction to the High Temperature Oxidation of Metals, 2006. doi:10.2277/0521480426.

[46] A.M. Alper, R.N. McNally, P.H. Ribbe, R.C. Doman, The System MgO-MgAl $\mathrm{O}_{4}, \mathrm{~J}$. Am. Ceram. Soc. 45 (1962) 263-268. doi:10.1111/j.1151-2916.1962.tb11141.x.

[47] O. Salas, H. Ni, V. Jayaram, K.C. Vlach, C.G. Levi, R. Mehrabian, Nucleation and growth of A12O3/metal composites by oxidation of aluminum alloys, J. Mater. Res. 6 (1991) 1964-1981. doi:10.1557/JMR.1991.1964.

[48] M. Valdez, K. Prapakorn, A.W. Cramb, S. Sridhar, Dissolution of alumina particles in $\mathrm{CaO}-\mathrm{Al} 2 \mathrm{O} 3-\mathrm{SiO}_{2}-\mathrm{MgO}$ slags, Ironnmaking Steelmak. (2002). doi:10.1179/030192302225001965.

[49] E.W. Hart, Introduction to Thermodynamics. D. C. Spanner. Academic Press, New York, 1964. xii Sci. 148 (1965) 1084. doi:10.1126/science.148.3673.1084.

[50] K. Larry, Foreword, in: N. Saunders, A.P. Miodownik (Eds.), CALPHAD Calc. Phase Diagrams, Pergamon, 1998: p. xvi. doi:https://doi.org/10.1016/S14701804(98)80020-5.D.

[51] Gaskell, Introduction to Thermodynamics of Materials, 2013. doi:10.1017/CBO9781107415324.004.

[52] H.A. Buchdahl, The Concepts of Classical Thermodynamics, Am. J. Phys. (1960). doi:10.1119/1.1935102.

[53] B.L. Tiwari, Thermodynamic properties of liquid Al-Mg alloys measured by the Emf method, Metall. Trans. A. 18 (1987) 1645-1651. doi:10.1007/BF02646148.

[54] J.L. Murray, A.J. McAlister, The Al-Si (Aluminum-Silicon) system, Bull. Alloy Phase Diagrams. (1984). doi:10.1007/BF02868729.

[55] Y.J. Bhatt, S.P. Garg, Thermodynamic study of liquid aluminum-magnesium alloys by vapor pressure measurements, Metall. Trans. B. 7 (1976) 271-275. doi:10.1007/BF02654926.

[56] N. Saunders, A review and thermodynamic assessment of the Al-Mg and $\mathrm{Mg}-\mathrm{Li}$ systems, Calphad. (1990). doi:10.1016/0364-5916(90)90040-7.

[57] J. Bloch, D.J. Bottomley, J.G. Mihaychuk, H.M. van Driel, R.S. Timsit, Magnesium surface segregation and its effect on the oxidation rate of the (111) surface of A1- 
1.45at\%Mg, Surf. Sci. 322 (1995) 168-176. doi:https://doi.org/10.1016/00396028(95)90027-6.

[58] N.F.A. Damoah, L.N.W., L. Zhang, Formation of the solid layer on the top of molten aluminum, (2010).

[59] E. Bergsmark, C.J. Simensen, P. Kofstad, The oxidation of molten aluminum, Mater. Sci. Eng. A. 120-121 (1989) 91-95. doi:10.1016/0921-5093(89)90723-5.

[60] J.J. Burton, E.S. MacHlin, Prediction of segregation to alloy surfaces from bulk phase diagrams, Phys. Rev. Lett. 37 (1976) 1433-1436. doi:10.1103/PhysRevLett.37.1433.

[61] X.-Y. Liu, P.P. Ohotnicky, J.B. Adams, C.L. Rohrer, R.W. Hyland, Anisotropic surface segregation in Al-Mg alloys, Surf. Sci. 373 (1997) 357-370. doi:10.1016/S0039-6028(96)01154-5

[62] M.P. Seah, Quantitative prediction of surface segregation, J. Catal. 57 (1979) 450-457. doi:10.1016/0021-9517(79)90011-3.

[63] H. Ehrenreich, F. Seitz, D. Turnbull, eds., Contributors to Volume 35, in: Academic Press, 1980: p. vii. doi:https://doi.org/10.1016/S0081-1947(08)60500-7.

[64] C. Kittel, Introduction to Solid State Physics, 2010. doi:10.1007/978-3-540-93804-0.

[65] R.C. Picu, D. Zhang, Atomistic study of pipe diffusion in Al-Mg alloys, Acta Mater. 52 (2004) 161-171. doi:10.1016/j.actamat.2003.09.002.

[66] D.T.L. Van Agterveld, G. Palasantzas, J.T.M. De Hosson, Magnesium surface segregation and oxidation in Al-Mg alloys studied with local probe scanning Augerscanning electron microscopy, Appl. Surf. Sci. 152 (1999) 250-258. doi:10.1016/S0169-4332(99)00323-2.

[67] A.R. Miedema, On the heat of formation of solid alloys II, J. Less Common Met. 46 (1976) 67-83. doi:10.1016/0022-5088(75)90034-X.

[68] F.J. Esposto, C.S. Zhang, P.R. Norton, R.S. Timsit, Segregation of Mg to the surface of an AlMg single crystal alloy and its influence on the initial oxidation at room temperature, Surf. Sci. 302 (1994) 109-120. doi:10.1016/0039-6028(94)91101-0. 